\title{
Yaks versus Tweets: Sentiment Discrepancy During a Social Crisis
}

\author{
Mehrdad Koohikamali \\ University of Redlands \\ Mehrdad_Koohikamali@Redlands.edu
}

\author{
Natalie Gerhart \\ Creighton University \\ NatalieGerhart@Creighton.edu
}

\begin{abstract}
People use social networks to get current information, express their emotions and ideas, and connect with others. During a social crisis, there is a heightened value in using a social network to get information. Unfortunately, using a social network during a social crisis also provides fertile grounds for uncertainties and rapid dissemination of misinformation. Currently, there are multiple types of social networks including traditional and anonymous social networks. This research considers the differences between these two types of social networks. During the 'Concerned Student 1950', a student activist group at the University of Missouri, crisis at the University of Missouri, we captured users' messages on two distinct anonymous and traditional social networks. Through sentiment analysis of datasets from Twitter and Yik Yak, we find that people express less total sentiment and more extremity on anonymous social networks. Results show extremity and length positively influence engagement, but total sentiment negatively influence engagement. These findings provide guidance for developers, law enforcement, and social network users.
\end{abstract}

\section{Introduction}

Social network (SN) use continues to rise among Americans, indicating an infiltration of SNs into the daily lives of all generations of online adults, no longer just millennials [20]. In 2016, according to the Pew Research Center, $62 \%$ of Americans claim SNs as a news source [19]. As a result, SNs have now entered the mainstream as a place for information for all of society, as well as a place to spur social change.

Specifically, multiple social movements have been identified as directly impacted by the use of SNs such as the Mumbai terror attacks, the Toyota recall, and the Seattle café shooting incident [35], the 2011 revolution in Egypt [36], Ferguson riots, and Baltimore riots [7, 23]. The recent "Black Lives Matter" movement began with just a hashtag in 2012, and the founders credit SNs for the success they have seen [46].

Because of the rate of dissemination of information on SNs, situations can escalate very quickly, sometimes leading to a social crisis. There are five key features of a crisis according to Pearson and Clair [40]: it should be an ambiguous situation, be unlikely to occur, have a short reaction time, be surprising, and require a decision to be made.

One such social crisis occurred at the University of Missouri (MU) in the fall of 2015. A group of students, named 'Concerned Student 1950' (CS1950), used SNs to bring attention to racism on their campus. Building on previous events from neighboring Ferguson, Missouri, CS1950 centered on black student experiences with racism on campus [8].

Meanwhile, several of their fellow students used SNs to agree or disagree with the message, sometimes interacting anonymously [26]. Using the anonymous SN application, Yik Yak, some observers made threats to the campus, resulting in arrests [57].

Yik Yak allowed geo-fenced communities to interact without individually identifying information, unlike traditional SNs which require a profile. With the veil of anonymity, people were able to be more critical of a situation than they might feel comfortable being on traditional SNs. As a result, reactions to a social crisis on the two platforms are likely different. In this research, we address two research questions: how do people engage on SNs during a social crisis, and how does anonymity influence engagement on SNs during a social crisis?

To address these research questions, we use text analytics on Twitter and Yik Yak posts as related to the CS1950 social crisis. Understanding how users express themselves differently is valuable to society as a whole, higher education administrator, and SN developers. The founders of Yik Yak explicitly condemned the way the SN app was used during the CS1950 crisis [3], indicating the designers overlooked uses of their app while developing the concept. As the global community relies more on SNs for political, professional, and social relationships, understanding the different uses of these networks is important.

From a theoretical perspective, we advance research models by providing a unique case study that measures sentiment and extremity of the message using text analytics. We further relate these indicators of emotion to overall engagement with the content of the message, which is an indicator of the reach of the 
message. Further, considering different uses of these SN offerings, we highlight the need for new divergent research models in each class to fully understand use behaviors.

\section{Literature Review}

\subsection{Traditional and Anonymous Social Networks}

$\mathrm{SNs}$, in their simplest form, provide an online environment for users to socialize with each other. Collectively, SNs now have over one billion global users [54]. Traditional SNs generally include three criteria: a semi-public profile on the network, a list of others to connect with, and a way to view and respond to others in the network [1]. Research on traditional SNs is vast, including continued use [22], privacy concerns $[11,25]$, and use of multiple SNs [41].

Anonymous SNs are a new class of SNs and a new technological artifact. They do not require, or allow, a personal profile. They also do not have a list of connected users, but instead rely on geo-fencing to connect communities that will engage. Anonymous SNs are an important SN though, because they fulfill the fundamental requirements of allowing social interactions for online users and, due to the geo-fencing, create a sense of community for the users. There is limited research on the use of anonymous SNs, although evaluation of why people are using anonymous SNs is becoming an increasingly important topic [e.g. , 17].

Anonymous SNs are primarily growing on college campuses [4], where geo-fenced communities are natural. The growth of anonymous SNs is partially due to the ability to share information without being identifiable [10]. Traditional SN users are seeking ways to communicate in a more private manner than traditional SNs allow [55].

Despite the ability to maintain social anonymity within the network of an anonymous SN, there are technical artifacts that trace users, such as IP addresses. As a result, law enforcement has the ability to identify users and prosecute those that present a threat to society. Specifically, a student at another university was arrested for an anonymous SN post about the CS1950 protests [13].

\subsection{Sentiments}

SNs contain a full range of information about opinions, debates, activities, intimate experiences, locations, relationships, rumors, false and fake news, and so on. Some users use SN functions to express their emotions. Sentiment is the information about an emotional state, judgement, or evaluation of people about a certain topic, event, or other people [49]. "Sentiment suggests a settled opinion reflective of one's feelings" (Pang and Lee 2008, pp.9). Monitoring public opinions about different topics is receiving more attention from practitioners and researchers [39]. For more efficient decision making about citizens, knowing the overall crowd opinion is important. For example, collective sentiment of U.S. Twitter users about a presidential candidate is an important indicator of the candidate's approval rate and chance of winning an election [6].

\subsection{Engagement}

The ultimate goal of a SN is to be social with others. On an SN, there are multiple ways for people to indicate they are engaged with another user's post. Engagement refers to going beyond viewing and instead creating emotional investment [38]. On SNs engagement occurs by reacting to the post, instead of just viewing it.

Research shows sentiments are associated with sharing behavior on SNs [49]. Reactions of people on SNs to unexpected social crises differ greatly [15]. During a social crisis, there are higher tendencies to express ideas, concerns, and responses more openly [9]. Because a social crisis occurs for a limited time, the efficiency of the message is more important; therefore, clearly expressing sentiment so there is less concern of interpretation is vital. Emotionally charged information on SNs diffuses more quickly, showing the efficiency it creates [49].

In addition, prior research shows negative sentiment postings on Facebook result in more user engagement in the form of comments than posts with a positive sentiment [48]. In the context of Twitter, a negative sentiment is related with the quantity and velocity diffusion of the messages [49]. The sentiment analysis of users' opinions on SNs during a crisis, can provide helpful resources to cope with the situation [15].

\section{Model Development}

Impression management theory suggests that people regulate how others perceive them [28]. Based on this theory, users of a traditional SN are actively crafting the impression that their network is interpreting. Research indicates that impression management causes people to divide their traditional SNs differently, to maintain a positive impression for their entire SN [18, 37]. As a result, those that are using a traditional $\mathrm{SN}$ are subject to maintaining positive impressions of themselves. 
On SNs, posts containing more sentiment increase users' attention and engagement [30]. On anonymous SNs, people do not need to acknowledge their behaviors and are therefore less vulnerable to the consequences of their behaviors on their offline identity [50]. People tend to share intimate personal information with strangers, a phenomenon known as "stranger on a train" [21]. Posts containing more sentiment on SNs would increase the likelihood viewers will get involved with it by reposting or commenting. Therefore, we hypothesize:

H1- If the total sentiment is higher it will illicit more engagement.

Extremity of a message can be defined as the high difference between its sentiment and overall sentiments of similar messages under the same situation. The sentiment extremity is different from total sentiment. Extremity reflects how one particular message is deviate from overall sentiments of other messages. When many messages have high total sentiments, only one message with a very low sentiment score may stand apart from the crowd and engage more people. Previous research shows that extreme information is more influential than moderate information [47]. For example, in the context of online reviews, extremity of the contents motivates users to get involved due to higher cognitive dissonance [27]. Similarly, on SNs people express their feelings and sentiments in the messages they post. Due to differences in social/personal involvement with a social crisis, people share very extreme information resulting in higher sentiment than the overall sentiment of messages posted by other individuals. Because extreme information is unequivocal it has more effect on users' behaviors [14]. Users engage more with extreme information to express their support or opposition. Consequently, we propose:

H2- If a message is extreme it will illicit more engagement.

Length of online comments is an indicator of the effort that people put behind them when they are being written [29]. As a result, many people have higher trust levels toward longer comments on online contexts [29]. Length of messages is often measured by word count [12]. The maximum length of tweets is 140 characters, while Yik Yak lets users compose up to 200-character messages. Several studies have identified the positive influence of length on helpfulness of contents, such as online reviews [33]. During social crisis situations, people want to gather as much information as possible [24]. Hence, when a message is longer, it makes people want to engage more with it. We suggest:
H3- If a message is longer it will illicit more engagement.

Contrastingly, users of anonymous SNs are not building or maintaining any impressions, because they are anonymous to the network of users. Anonymity can cause people to cyberbully [31] and ultimately behave more aggressively [32]. Essentially, users of an anonymous SN are able to hide behind their screens, as long as they do not post anything that is threatening enough for law enforcement to get involved. Therefore, we propose the following hypothesis:

H4a- If using an anonymous $\mathrm{SN}$, the effect of total sentiment of a message on engagement will be higher.

The ability to remain socially anonymous reduces the fear users have of disapproval, censorship, and evaluation by the network [42]. Anonymity encourages users to be more honest in their interactions [42]. If a common identity is present, anonymity positively influences social influence [43]. Prosocial words are used more in anonymous groups than groups with known identity [43]. In addition, people tend to be more open and honest when they perceive anonymity is present. For example, anonymity on SNs provides a place of excessive freedom for sharing content [16]. Because social presence (i.e. an identifiable profile) decreases the extremity in discussions [45] on SNs, anonymity makes it more convenient for users to be more extreme. Thus, we suggest:

H4b- If using an anonymous $\mathrm{SN}$, the effect of extremity on engagement will be higher.

Similarly, when using anonymous SNs people are expected to express their ideas, thoughts, and emotions more explicitly. As a result, a message in an anonymous SN when longer has a potential to include more unfiltered content.

H4c- If using an anonymous $\mathrm{SN}$, the effect of length on engagement will be higher. 


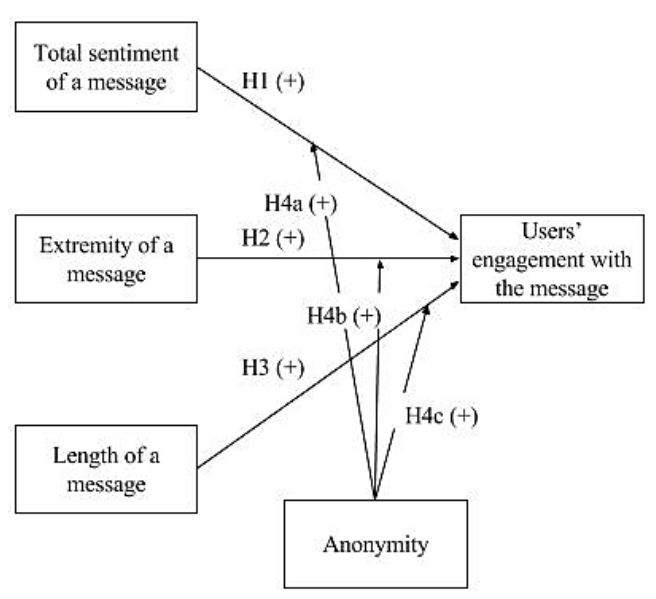

Figure 1. Proposed research model of user-message engagement during a social crisis

\section{Methodology}

To assess our hypotheses, we downloaded data from two SNs immediately following the CS1950 incident at MU in the fall of 2015. Research indicates there are stronger reactions to an event immediately following the event, than later [56]. Yik Yak, an anonymous $\mathrm{SN}$, was selected to gather anonymous data, because it had a high engagement rate on college campuses at the time. Yik Yak could only be accessed via smartphones, limiting the ability to scrape data, and was therefore manually collected by the researchers using screenshots. A total of 1042 unique Yaks were captured. For identified data, Twitter was chosen to be representative of traditional SNs. Twitter is the best SN to contrast with Yik Yak because the feeds generally have a similar, short, feel, and younger Americans are more likely to use Twitter than their older counterparts [20]. We used \#Mizzou and keyword Mizzou to extract tweets about the event. By using a Twitter API developed by authors, a total of 3476 tweets were downloaded. The resulting tweets are likely to be representative of similar demographics as Yik Yak, although tweets are not geo-fenced. Therefore, the datasets are similar, but distinct based on the intents and purposes of each SN. After removing duplicates and irrelevant data, a total of 834 Yaks and 3024 tweets were collected about the CS1950 incident from November 10-13, 2015. Using this data, we next conducted sentiment analysis.

The goal of sentiment analysis is to capture favorability of a text on a given topic using natural language processing [39]. Traditional sentiment analysis methods are based on lexicons to determine the positivity or negativity of words and then calculate the polarity of the text [5]. Inability of traditional sentiment analysis methods to capture the actual meaning of words in different contexts is the motivating factor for more granular techniques to provide implicit and explicit sentiment expressions [53]. More advanced techniques provide a continuous sentiment measure to determine sentiment-level polarity [58]. In this study, Sentistrength software [51] was used to detect the positive and negative sentiment strength of the collected Yik Yak and Twitter posts. The software is a free tool available to academia and it has been tested and verified in previous research [44]. For each message, a positive sentiment is indicated by a score from 1 (neutral) to 5 (strongly positive), a negative sentiment score is indicated by a score of -5 (strongly negative) to -1 (neutral). We calculated the total sentiment of each message by using the sum of absolute values of negative and positive sentiment scores in the following formula:

Total Sentiment $=$ Positive Sentiment Score $+A B S$ (Negative Sentiment Score)

Sentiment extremity of each message is calculated based on the depreciation of total sentiment from the average sentiment scores of each dataset for tweets and Yaks using the following formula:

Sentiment Extremity $=$ Total Sentiment - Average Sentiment Score

We also created one dummy variable, anonymity, to test the moderation effect of anonymity on three relationships with engagement. Yaks are considered to be anonymous and received the score of 1 and tweets received the score of zero. Finally, to determine the engagement with the post, we used two measures. On Yik Yak, a post gains in popularity, and builds the user "Yak Karma" on the SN, when it is up voted by the community. A separate feed displays the most popular Yaks in the geo-fenced community. On Twitter, individuals have the opportunity to "retweet" a complete tweet or quote the tweet in their own post. Both of these are indicators of engagement with the message.

Twitter provides a twitter activity dashboard, which includes a measure for Twitter engagement. Twitter engagement for each message is the amount of interactions with each tweet however it is only available for the user who posts the message [52]. To determine engagement as an external observer, the number of retweets is an appropriate indicator.

\section{Results}

After data collection, we performed multiple steps in our analysis. The first step was to analyze the descriptive 
statistics (presented in Table 1). Based on this, the data is not normal. There are very high standard deviations and various ranges. As a result, to adjust the overdispersion of engagement, there was a need for a logarithmic transformation $[2,41]$. To test the hypotheses, we used the following regression model:

$\log ($ Engagement $)=\beta_{0}+\beta_{1}$ Total Sentiment + $\beta_{2}$ Sentiment Extremity $+\beta_{3}$ Length + $\beta_{4}$ Anonymity $+\beta_{5}$ Total Sentiment $\times$ Anonymity $+\beta_{6}$ Sentiment Extremity $\times$ Anonymity $+\beta_{7}$ Length $\times$ Anonymity

Table 1. Descriptive statistics

\begin{tabular}{|c|c|c|c|}
\hline Variable & Range & Median & Mean (SD) \\
\hline $\begin{array}{c}\text { Engagement } \\
\text { (Retweets) }\end{array}$ & $0-8694$ & 83 & $\begin{array}{c}722.64 \\
(1386.23)\end{array}$ \\
\hline $\begin{array}{c}\text { Engagement } \\
\text { (Upvotes) }\end{array}$ & $-4-222$ & 7 & $13.41(22.61)$ \\
\hline $\begin{array}{c}\text { Total Sentiments } \\
\text { (Twitter) }\end{array}$ & $2-8$ & 3 & $3.35(1.27)$ \\
\hline $\begin{array}{c}\text { Total Sentiments } \\
\text { (Yik Yak) }\end{array}$ & $2-8$ & 3 & $3.27(1.20)$ \\
\hline $\begin{array}{c}\text { Sentiment } \\
\text { Extremity (Twitter) }\end{array}$ & $0.35-$ & 1.35 & $1.08(0.68)$ \\
\hline $\begin{array}{c}\text { Sentiment } \\
\text { Extremity } \\
\text { (Yik Yak) }\end{array}$ & $0.27-$ & 0.73 & $1.00(0.66)$ \\
\hline $\begin{array}{c}\text { Length } \\
\text { (Twitter) }\end{array}$ & $15-140$ & 137 & $122.36(24.52)$ \\
\hline $\begin{array}{c}\text { Length } \\
\text { (Yik Yak) }\end{array}$ & $1-417$ & 64 & $78.03(59.53)$ \\
\hline $\begin{array}{c}\text { Positive Sentiment } \\
\text { (Twitter) }\end{array}$ & $1-5$ & 1 & $1.36(0.57)$ \\
\hline $\begin{array}{c}\text { Positive Sentiment } \\
\text { (Yik Yak) }\end{array}$ & $1-5$ & 1 & $1.42(0.65)$ \\
\hline $\begin{array}{c}\text { Negative Sentiment } \\
\text { (Twitter) }\end{array}$ & $-1--5$ & -2 & $-1.98(1.07)$ \\
\hline $\begin{array}{c}\text { Negative Sentiment } \\
\text { (Yik Yak) }\end{array}$ & $-1--5$ & -2 & $-1.90(1.05)$ \\
\hline
\end{tabular}

Next, we tested for multicollinearity by analyzing the correlation matrix and Variance Inflation Factor (VIF) values (Table 2). VIF indicates the degree of multicollinearity and measures the multicollinearity effect on regression results [34]. The results indicate relatively medium correlations. As seen in the correlation table, there is high correlation between total sentiment and sentiment extremity. This is expected the more total sentiments in a message, the more likely it is to contain extreme sentiments. We checked for multicollinearity to make sure that high correlation between total sentiment and sentiment extremity is not an issue for our regression analysis. Due to medium correlation between some variables, we checked the VIF of independent variables. The results of the analysis showed all VIF values obtained are lower than 10 and there is no multicollinearity symptom.
Table 2. Correlation matrix

\begin{tabular}{|c|l|c|c|c|c|}
\hline \multicolumn{2}{|l|}{ Variable } & $\mathbf{1}$ & $\mathbf{2}$ & $\mathbf{3}$ & $\mathbf{4}$ \\
\hline 1 & Engagement & 1.00 & $0.12^{* *}$ & -0.02 & $0.21^{* *}$ \\
\hline 2 & $\begin{array}{l}\text { Sentiment } \\
\text { Extremity }\end{array}$ & $0.12^{* *}$ & 1.00 & $.42^{* *}$ & $0.08^{* *}$ \\
\hline 3 & $\begin{array}{l}\text { Total } \\
\text { Sentiments }\end{array}$ & -0.02 & $0.42^{* *}$ & 1.00 & $0.29^{* *}$ \\
\hline 4 & Length & $0.21^{* *}$ & $0.08^{* *}$ & $0.29^{* *}$ & 1.00 \\
\hline$* *$ Correlation is significant at the 0.01 level (2-tailed). \\
\hline
\end{tabular}

Having satisfied these conditions, we next performed the regression analysis. The resulting model is significant $(\mathrm{F}=114.589, \mathrm{p}<0.001)$. The resulting variance explained is $15.1 \%$. All of the variables are significant $(\mathrm{p}<0.001)$. Complete results of the analysis are shown in Table 3 . Results of the analysis indicate $\mathrm{H} 2, \mathrm{H} 3, \mathrm{H} 4 \mathrm{a}$ are significant, while $\mathrm{H} 1, \mathrm{H} 4 \mathrm{~b}$, and $\mathrm{H} 4 \mathrm{c}$ are in the opposite direction of what was hypothesized. Extremity and length are positively related to engagement, supporting $\mathrm{H} 2$ and $\mathrm{H} 3$. The moderation effect of anonymity on the relationship between total sentiment and engagement is positive and significant, supporting H3a. On the other hand, total sentiment is negatively related with engagement, opposite to the direction of H1. The moderation effect of anonymity on the relationship between extremity and engagement and length and engagement is negative, contrary to our hypotheses $\mathrm{H} 3 \mathrm{~b}$ and $\mathrm{H} 3 \mathrm{c}$.

Table 3. Regression Results and Collinearity Test

\begin{tabular}{|l|c|c|c|c|}
\hline \multicolumn{1}{|c|}{ Variable } & B & Std. B & t & VIF \\
\hline Total Sentiments & $\beta_{1}$ & -0.181 & $-9.01 * *$ & 1.39 \\
\hline Extremity & $\beta_{2}$ & 0.202 & $10.01 * *$ & 1.50 \\
\hline Length & $\beta_{3}$ & 0.187 & $5.57 * *$ & 3.376 \\
\hline Anonymity & $\beta_{4}$ & -0.255 & $-2.40 * *$ & 9.005 \\
\hline $\begin{array}{l}\text { Anonymity } \times \text { Total } \\
\text { Sentiment }\end{array}$ & $\beta_{5}$ & 0.282 & $5.629 * *$ & 8.870 \\
\hline $\begin{array}{l}\text { Anonymity } \times \\
\text { Extremity }\end{array}$ & $\beta_{6}$ & -0.168 & $-3.58 * *$ & 3.57 \\
\hline Anonymity $\times$ Length & $\beta_{7}$ & -0.169 & $-2.67 * *$ & 6.392 \\
\hline$* *$ Significant at the 0.001 level. (2-tailed). \\
\hline
\end{tabular}

\section{Discussion}

The results of this study indicate differences between anonymous and traditional SNs. When anonymity is added to the model as a moderator, the results show more extremity and more total sentiment increase engagement.

On both SNs, length, total sentiment, and extremity increase engagement. In language, there is an expression that the "squeaky wheel gets the oil" to explain that if a person complains loud enough and long enough, they will get attention. Our findings show the same is true for SNs. This suggests that people are more likely to engage 
with messages that are clearer (because they are longer), have a more expressive message (based on polarity), and are more extreme. Despite this finding, SN users are interested in tools to help increase privacy [55]. The results of the moderation effect reflect this hope for more privacy.

The most interesting finding of these results is the moderating effect of anonymity. Posts on an anonymous $\mathrm{SN}$ are more impactful when they are polarizing and extreme. This aligns with the intent of anonymous SNs to allow people to express more honest opinions without repercussions. Anonymity is associated with lower inhibitions, which increases willingness to post less socially accepted viewpoints [42].

Another finding is about the moderation effect of anonymity on the positive effect of length on engagement. While lengthier tweets result in higher engagement, the effect is reversed for anonymous Yaks. This can be explained ny the fact that people should be on-point and concise when there is no identity. Users pay less attention to a stranger's message on an anonymous $\mathrm{SN}$ if it is very long, compared to a potentially known source on a traditional SN, no matter how long it is people may have higher tendencies to engage with it.

These findings have important implications. Prior research shows that $\mathrm{SNs}$ can be a useful tool for emergency officials during a social crisis [56]. As a result, it is important for emergency response teams to understand the ways that different $\mathrm{SNs}$ are used to convey messages. This research can help with choosing the most useful platform, as well as biases to be aware of during a social crisis. Further, the development of SNs can benefit from understanding how different SNs are used. Anonymous SNs should be alert to the potential misuses and consider ways to combat the spread of negative messages. Some ideas include a more immediate response to flagged posts as well as constant monitoring, potentially by Artificially Intelligent machines.

As with all research, this study is subject to certain limitations. The measure for engagement between anonymous and traditional SNs is not the same. Retweet versus Up votes are two distinct ways to interact online; however, when comparing two different systems, there are certain constraints that cannot be changed. We feel that these measures are the best for determining engagement because they are both the most powerful way a person can show agreement on each SN.

Secondly, this study is limited to publicly available data. Yik Yak data is geo-fenced, however there is a "peek" option to allow anyone to see data from other locations. Twitter data can be set to private or public. If it is private, data is only accessible to users that the poster allows; therefore, the data used in this study is all public data. Arguably, people could be even more honest, and even more extreme if their profile is private. People use segmentation strategies to change their image on SNs [18].

Third, the sentiment analysis software that we used for the analysis can produce several measures of textual information. However, it is unable to detect specific contexts, such as racism. Fourth, this study focuses on a crisis event because it ensures the content of posts is similar. Determining if these results are similar in other events that are not a social crisis, such as a natural disaster or a celebratory event, could strengthen the generalizability of our results.

Finally, the explanatory power of the model, as stated in the results, is moderate. In the future by inducing more predictors a higher explanatory power can be achieved. Therefore, this paper serves only as the beginning of research in the area of anonymity on SNs. Unfortunately, as of May 2017 Yik Yak has officially been shut down due to several reasons; therefore, there are even fewer options to check the effect of anonymity during a social crisis.

\section{Conclusion}

With this research, we provide the only analysis of actual anonymous SN data, that we are aware of. By looking at the moderating effect of anonymity on sentiment and extremity we gain better understanding of what causes people to engage with a traditional and anonymous SN, particularly during a social crisis. This has valuable implications for law enforcement and society as a whole as they try to trace and understand a community of users during a social crisis. This also has important design implications as Yik Yak tried to reshape its application to more closely align with the developers' intentions. Theoretically, we offer new insights into the differences between anonymous and traditional SNs using text analytics. These differences suggest the need for different theoretical underpinnings, particularly the role of privacy and honesty, in future research on these two divergent systems.

\section{References}

[1] Boyd, D.M. and Ellison, N.B. Social network sites: Definition, history, and scholarship. Journal of Computer-Mediated Communication 13, 1 (2007), 210-230.

[2] Brehm, S. and Brehm, J. Psychological Reactance a Theory of Freedom and Control - Brehm,Ss, Brehm,Jw. Academic Press, 2013.

[3] Buggington, B. Yik Yak Legal. Yik Yak Blog, 2015.

[4] Burns, H. Yik Yak app stirring up chatter on 
college campuses. USA Today, 2014.

[5] Cambria, E., Schuller, B., Xia, Y., and Havasi, C. New Avenues in Opinion Mining and Sentiment Analysis. IEEE Intelligent Systems (2), April (2013), 15-21.

[6] Ceron, a., Curini, L., Iacus, S.M., and Porro, G. Every tweet counts? How sentiment analysis of social media can improve our knowledge of citizens' political preferences with an application to Italy and France. New Media \& Society 16, 2 (2013), 1-19.

[7] De Choudhury, M., Jhaver, S., Sugar, B., and Weber, I. Social Media Participation in an Activist Movement for Racial Equality. International Conference on Web and Social Media, (2016).

[8] Concerned Student 1950. Concerned Student 1-9-50 List of Demands. 2015.

[9] Coombs, W.T. Crisis management and communications. Institute for Public Relations, 2007, 1-14. http://www.instituteforpr.org/crisismanagement-and-communications/. [10] Diaz, C., Troncoso, C., and Serjantov, A. On the Impact of Social Network Profiling on Anonymity. In Privacy Enhancing Technologies. 2008, 44-62.

[11] Dwyer, C., Hiltz, S., and Passerini, K. Trust and privacy concern within social networking sites: A comparison of Facebook and MySpace. Americas Conference on Information Systems, (2007), 339.

[12] Einar, B., Havro, L.J., and Moen, O. An Empirical Investigation of Self-Selection Bias and Factors Influencing Review Helpfulness. International Journal of Business and Management 10, 7 (2015), 16-31.

[13] Eligon, J. At University of Missouri , Black Students See a Campus Riven by Race. The New York Times, 2015.

[14] Forman, C., Ghose, A., and Wiesenfeld, B.

Examining the relationship between reviews and sales: The role of reviewer identity disclosure in electronic markets. Information Systems Research 19, 3 (2008), 291-313.

[15] Gaspar, R., Pedro, C., Panagiotopoulos, P., and Seibt, B. Beyond positive or negative: Qualitative sentiment analysis of social media reactions to unexpected stressful events. Computers in Human Behavior 56, (2016), 179-191.

[16] Gehl, R.W. Power/freedom on the dark web: A digital ethnography of the Dark Web Social Network. New Media \& Society 18, 7 (2016), 1219 -1235.

[17] Gerhart, N. and Koohikamali, M. Anonymously Social Networking: A Great Migration. Twenty-first Americas Conference on Information Systems, (2015), 1.

[18] Gerhart, N. and Sidorova, A. The Effect of Network Characteristics on Online Identity Management Practices. Journal of Computer Information Systems, .
[19] Gottfried, J. and Shearer, E. News Use Across Social Media Platforms 2016. 2016.

[20] Greenwood, S., Perrin, A., and Duggan, M. Social media update. 2016.

[21] Hollenbaugh, E.E. and Everett, M.K. The effects of anonymity on self-disclosure in blogs: An application of the online disinhibition effect. Journal of Computer-Mediated Communication 18, 3 (2013), 283-302.

[22] Hu, T. and Kettinger, W.J. Why People Continue to Use Social Networking Services: Developing a Comprehensive Model. Proceedings of the 29th Internation Conference on Information Systems, (2008).

[23] Koohikamali, M. and Kim, D.J. Rumor and truth spreading patterns on social network sites during social crisis: Big data analytics approach. Lecture Notes in Business Information Processing 258, (2016).

[24] Koohikamali, M. and Kim, D.J. Rumor and truth spreading patterns on social network sites during social crisis: Big data analytics approach. Lecture Notes in Business Information Processing 258, (2016), 166170.

[25] Koohikamali, M., Peak, D.A., and Prybutok, V. Beyond Self-Disclosure: Disclosure of Information about Others in Social Network Sites. Computers in Human Behavior 69, (2017), 29-42.

[26] Kravarik, J. A Familiar Protest: Missour Racism Demonstrations Are Rooted in History. CNN.com, 2015.

[27] Kuan, K.K.Y., Hui, K.-L., Prasarnphanich, P., and Lai, H.-Y. What Makes a Review Voted? An Empirical Investigation of Review Voting in Online Review Systems. Journal of the Association for Information Systems 16, 1 (2015), 48-71.

[28] Leary, M.R. and Kowalski, R.M. Impression Management: A Literature Review and TwoComponent mModel. Psychological Bulletin 107, I (1990), 34-47.

[29] Lucassen, T. and Schraagen, J.M. Trust in Wikipedia : How Users Trust Information from an Unknown Source. The workshop on Information credibility: ACM, (2006), 19-26.

[30] Mayshak, R., Sharman, S.J., and Zinkiewicz, L. The impact of negative online social network content on expressed sentiment, executive function, and working memory. Computers in Human Behavior 65, (2016), 402-408.

[31] Mishna, F., Saini, M., and Solomon, S. Ongoing and online: Children and youth's perceptions of cyber bullying. Children and Youth Services Review 31, 12 (2009), 1222-1228.

[32] Moore, M.J., Nakano, T., Enomoto, A., and Suda, T. Anonymity and roles associated with aggressive posts in an online forum. Computers in Human 
Behavior 28, 3 (2012), 861-867.

[33] Mousavizadeh, M., Koohikamali, M., and Salehan, M. The Effect of Central and Peripheral Cues on Online Review Helpfulness : A Comparison between Functional and Expressive Products. Icis, (2015), 1-22.

[34] O'Brien, R.M. A caution regarding rules of thumb for variance inflation factors. Quality and Quantity 41, 5 (2007), 673-690.

[35] Oh, O., Agrawal, M., and Rao, H.R. Community Intelligence and Social Media Services: A Rumor Theoretic Analysis of Tweets During Social Crises. MIS Quarterly 37, 2 (2013), 407-426.

[36] Oh, O., Eom, C., and Rao, H.R. Research Note Role of Social Media in Social Change: An Analysis of Collective Sense Making During the 2011 Egypt Revolution. Information Systems Research 26, 1 (2015), 210-223.

[37] Ollier-Malaterre, A., Rothbard, N.P., and Berg, J.M. When Worlds Collide in Cyberspace: How Boundary Work in Online Social Networks Impacts Professional Relationships. Academy of Management Review 38, 4 (2013), 645-669.

[38] Pagani, M. and Mirabello, A. The Influence of Personal and Social-Interactive Engagement in Social TV Web Sites. International Journal of Electronic Commerce 16, 2 (2011), 41-67.

[39] Pang, B. and Lee, L. Opinion Mining and Sentiment Analysis. Found.Trends Inf.Retr. 2, 1-2 (2008), 1-135.

[40] Pearson, C.M. and Clair, J.A. Reframing Crisis Management. The Academy of Management Review 23, 1 (1998), 59-76.

[41] Petrocchi, N., Asnaani, A., Martinez, A.P., Nadkarni, A., and Hofmann, S.G. Differences Between People Who Use Only Facebook And Those Who Use Facebook Plus Twitter. International Journal of Human-Computer Interaction, (2014). [42] Pinsonneault, A. and Heppel, N. Anonymity in Group Support Systems Research: A New Conceptualization, Measure, and Contingency Framework. Journal of Management Information Systems 14, 3 (1997), 89-108.

[43] Postmes, T., Spears, R., Sakhel, K., and de Groot, D. Social Influence in Computer-Mediated Communication: The Effects of Anonymity on Group Behavior. Personality and Social Psychology Bulletin 27, 10 (2001), 1243-1254.

[44] Salehan, M. and Kim, D.J. Predicting the performance of online consumer reviews: A sentiment mining approach to big data analytics. Decision Support Systems 81, (2016), 30-40.

[45] Sia, C.L., Tan, B.C.Y., and Wei, K.K. Group polarization and computer-mediated communication: Effects of communication cues, social presence, and anonymity. Information Systems Research 13, 1 (2002), 70-90.

[46] Sidner, S. and Simon, M. The Rise of Black Lives Matter: Trying to Break the Cycle of Violence and Silence. CNN.com, 2015.

[47] Skowronski, J.J. and Carlston, D.E. Social judgment and social memory: The role of cue diagnosticity in negativity, positivity, and extremity biases. Journal of personality and social psychology 52, 4 (1987), 689.

[48] Stieglitz, S. and Dang-Xuan, L. Impact and Diffusion of Sentiment in Political Communication An Empirical Analysis of Public Political Facebook Pages. ECIS 2012 Proceedings, (2012), 5-15.

[49] Stieglitz, S. and Dang-Xuan, L. Emotions and Information Diffusion in Social Media-Sentiment of Microblogs and Sharing Behavior. Journal of Management Information Systems 29, 4 (2013), 217248.

[50] Suler, J. The online disinhibition effect. CyberPsychology \& Behavior 7, 3 (2004), 321-326. [51] Thelwall, M., Buckley, K., Paltoglou, G., and Cai, D. Sentiment Strength Detection in Short Informal Text. The American Society for Informational science and technology 61, 12 (2010), 2544-2558.

[52] Twitter. Twitter. 2017.

https://support.twitter.com/articles/20171990.

[53] Villarroel Ordenes, F., Ludwig, S., de Ruyter, K., Grewal, D., and Wetzels, M. Unveiling What is Written in The Stars: Analyzing Explicit, Implicit and Discourse Patterns of Sentiment in Social Media. Journal of Consumer Research Forthcomin, (2016). [54] Wagner, K. Facebook Passes 1 Billion Monthly Mobile Users. Mshable, 2014.

http://mashable.com/2014/04/23/facebook-1-billionmobile-users/.

[55] Wang, G., Wang, B., Wang, T., Nika, A., Zheng, H., and Zhao, B.Y. Whispers in the Dark: Analysis of an Anonymous Social Network. Proceedings of the 2014 Conference on Internet Measurement, (2014). [56] Williams, M.L. and Burnap, P. Cyberhate on Social Media in the Aftermath of Woolwich: A Case Study in Computational Criminology and Big Data. British Journal of Criminology 56, 2 (2016), 211-238. [57] Yan, H. and Stapleton, A. University of Missouri Students Report Threats; Police Quell KKK Rumors. CNN.com, 2015.

[58] Yu, Y., Duan, W., and Cao, Q. The impact of social and conventional media on firm equity value: A sentiment analysis approach. Decision Support Systems 55, 4 (2013), 919-926. 